may be used in general practice, where most patients with ulcers are seen.

Secondly, intermittent treatment is more economical: less drug is required than for maintenance treatment. Assuming that on average a six-week course of cimetidine $1 \mathrm{~g}$ daily is required to heal a duodenal ulcer and provided that there are no contraindications, for 100 patients treated intermittently during one year about 200 courses would be required. The trade price of cimetidine is $£ 13.22$ per hundred 200 -mg tablets, excluding dispensing fees:; based on this figure the drug cost for such treatment is therefore about $£ 5500$. (I have excluded any costs incurred owing to a delay in restarting treatment, leading to worsening of symptoms and loss of time at work, or to the occurrence of haemorrhage or perforation.) In contrast, if after initial treatment these patients are put on prophylactic low-dose maintenance treatment with cimetidine $400 \mathrm{mg}$ nightly for a year, and allowing for $13 \%$ to have a symptomatic relapse requiring retreatment with full doses of cimetidine, the drug cost is about $£ 12600$. Therefore, though maintenance treatment (or surgery) is the only suitable method of treating several patients, in most cases intermittent treatment provides a cheaper method of obtaining satisfactory results.

Thirdly, patients who rapidly and repeatedly relapse each time cimetidine is withdrawn are easily recognised; they may confidently be selected for maintenance treatment or surgery.

In conclusion, given the uncertainties of long-term low-dose maintenance treatment with cimetidine, intermittent treatment provides a reasonable alternative for the longer-term treatment of most patients.

This study would not have been possible without help from many people. Mrs Denise Grove, my former secretary, helped to interview patients and develop the open referral system for gastroscopy, which was ably continued by Mrs Janice Law, who also typed the paper, and Mrs Stephanie Hardy. Sister J Brooksbank, her day-ward staff, Nurse A Malia, and the endoscopy nurses coped with ever-increasing numbers of patients. The consultant physicians and surgeons and general practitioners continued to refer patients. The patients continued to attend largely to support research. Drs C D Holdsworth (consultant physician, Royal Hallamshire Hospital, Sheffield), A M Cantor, and A R Haste (consultant physicians, Rotherham) made many helpful comments. Mr A Tunstill and his colleagues (medical illustrations, Royal Hallamshire Hospital) and Mr Barry Farmer (medical illustrations, Rotherham Hospital) provided the illustrations. The Rotherham Area Health Authority continues to support my work, despite financial problems. I am indebted to all these and to others not mentioned.

This paper is dedicated to the memory of the late Sister Dallas Walker, who contributed so much to my work but tragically died when so young.

\section{References}

${ }^{1}$ Bardhan KD. Cimetidine in duodenal ulceration. In: Wastell C, Lance P, eds. Cimetidine. The Westminster Hospital Symposium. Edinburgh, London and New York: Churchill Livingstone, 1978:31-56.

2 Burland WL, Hawkins BW, Horton RJ, Beresford J. The longer-term treatment of duodenal ulcer with cimetidine. In: Wastell C, Lance P, eds. Cimetidine. The Westminster Hospital Symposium. Edinburgh, London and New York: Churchill Livingstone, 1978: 66-78.

3 Bardhan KD, Saul DM, Edward JL, et al. Double-blind comparison of cimetidine and placebo in the maintenance of healing of chronic duodenal ulceration. Gut 1979;20:158-62.

Hansky J, Korman MG. Long-term cimetidine in duodenal ulcer disease. Digestive Diseases and Sciences $1979 ; 24: 465-70$.

5 Berstad A, Aadland E, Carlsen E, Myren J, Semb LS, Kruse-Jensen A. Maintenance treatment of duodenal ulcer patients with a single bedtime dose of cimetidine. Scand $\mathcal{F}$ Gastroenterol 1979;14:827-31.

${ }^{6}$ Gudmand-Hoyer E, Jensen KB, Krag E, et al. Prophylactic effect of cimetidine in duodenal ulcer disease. $B r$ Med $₹$ 1978;i:1095-7.

7 Dronfield MW, Batchelor AJ, Larkworthy W, Langman MJS. Controlled trial of maintenance cimetidine treatment in healed duodenal ulcer: short and long-term effects. Gut $1979 ; 20: 526-30$.

${ }^{8}$ Monthly Index of Medical Specialities (MIMS). $1980 ; 22:(4): 45$.

(Accepted 28 April 1980)

\title{
Obstetric epidural analgesia and postural hypotension
}

\author{
E MOSS, R MACDONALD
}

\section{Summary and conclusions}

Supine and erect arterial pressures were measured daily for six to seven days after delivery in 100 patients, of whom 50 had received epidural analgesia. There was no difference in the magnitude of postural hypotension between the epidural and control groups on any day after delivery, although in both groups the hypotension was greater during the first two days due almost entirely to changes in systolic arterial pressure. The incidence of dizziness on standing was similar in both groups $(9 \%)$.

Thus postural hypotension is no more common in women who have received epidural analgesia than in others. All patients should be helped out of bed after delivery, and any patient who experiences dizziness should have her blood pressure measured until the dizziness disappears.

St James's University Hospital, Maternity Unit, Leeds LS9 TTF

E MOSS, MB, FFARCS, senior registrar in anaesthetics (present appointment: consultant anaesthetist, General Infirmary, Leeds)

R MACDONALD, PHD, FFARCS, consultant anaesthetist

\section{Introduction}

Briggs et $a^{1}$ reported a case of persistent severe postural hypotension after lumbar epidural analgesia during labour in a 26-year-old woman. They attributed this hypotension, which was still present three months after she received the analgesia, to an idiosyncratic reaction to bupivacaine causing a prolonged sympathetic block. To establish whether this case was just an exaggeration of a normal finding or was unique we undertook a study to determine the incidence of postural hypotension in the first week after delivery in patients who had received epidural analgesia for pain relief in labour.

\section{Patients and methods}

We studied 100 patients, of whom 50 received continuous lumbar epidural analgesia during labour (epidural group); the remaining 50 received pethidine or nitrous oxide, or both, if they required analgesia (control group). Only patients booked for a 10-day stay in hospital were included in the study. No patient lost more than $200 \mathrm{ml}$ of blood. Patients in the control group were chosen to match as closely as possible the age, parity, duration of labour, and date of delivery of patients in the epidural group.

Arterial pressure was measured daily until discharge in each 
patient, always in the supine position first and then the erect position. It was measured indirectly by using the Korotkoff sounds, the same sphygmomanometer and the same arm being used each time. In the first 10 patients in each group arterial pressures were measured in both the morning and the afternoon, but no significant difference was seen between the two readings, so for the remainder of the study only daily readings were taken. At the time of each measurement the patient was asked whether she felt dizzy on standing and her answer recorded. The changes in systolic and diastolic arterial pressures on assuming erect posture were calculated for each pair of readings, and the daily mean changes for the two groups were compared using Student's $t$ test. The changes in systolic and diastolic arterial pressures on standing, in both groups on each day, were tested for significance using a paired $t$ test. In addition, those patients in whom the epidural analgesia had lasted longer than 10 hours were compared with control patients whose labours had been of similar duration. This was to assess whether increased duration of sympathetic blockade consequent on long epidural analgesia contributed to postpartum postural hypotension.

\section{Results}

The epidural group consisted of 45 primigravidae and five multigravidae (average age 23 years (range 15-34 years)), and the control group of 39 primigravidae and 11 multigravidae (average age 22 years (range 16-31 years)). The average duration of labour in the epidural group was 11 hours (range 2-29 hours), which was significantly longer $(0.01>p>0.001)$ than that in the control group (average 8 hours; range 2-19 hours). Comparison of daily mean supine arterial pressures

TABLE I-Mean changes in systolic arterial pressure on standing $(\mathrm{mm} \mathrm{Hg})$

\begin{tabular}{|c|c|c|c|c|c|c|c|}
\hline & \multicolumn{7}{|c|}{ Day } \\
\hline & 1 & 2 & 3 & 4 & 5 & 6 & 7 \\
\hline $\begin{array}{l}\text { No of patients } \\
\text { Mean change } \\
\text { SEM } \\
\text { p }^{*}\end{array}$ & $\begin{aligned} & 50 \\
&-11.5 \\
& 1.7 \\
&<0.001\end{aligned}$ & $\begin{array}{c}\quad E p i \\
47 \\
-7.5 \\
1.9 \\
<0.001\end{array}$ & $\begin{array}{l}\text { dural grc } \\
49 \\
-5.7 \\
1.4 \\
<0.001\end{array}$ & $\begin{array}{l}\text { up } \\
44 \\
-4.7 \\
1.4 \\
<0.01\end{array}$ & $\begin{array}{c}47 \\
-4.9 \\
1.9 \\
<0.02\end{array}$ & $\begin{array}{l}42 \\
-2 \cdot 1 \\
1.6\end{array}$ & $\begin{array}{r}27 \\
-0 \cdot 4 \\
3 \cdot 2\end{array}$ \\
\hline $\begin{array}{l}\text { No of patients } \\
\text { Mean change } \\
\text { SEM } \\
\text { p }^{*}\end{array}$ & $\begin{array}{c}48 \\
-11.4 \\
2.3 \\
<0.001\end{array}$ & $\begin{array}{c}47 \quad C o \\
-7.7 \\
1.9 \\
<0.001\end{array}$ & $\begin{array}{l}\text { ntrol gro } \\
49 \\
-3.6 \\
1.6 \\
<0.05\end{array}$ & $\begin{array}{l}p \\
48 \\
-3.2 \\
1.3 \\
<0.02\end{array}$ & $\begin{array}{r}48 \\
-3.4 \\
1.9\end{array}$ & $\begin{array}{c}45 \\
-4 \cdot 2 \\
1 \cdot 3 \\
<0.01\end{array}$ & $\begin{array}{r}33 \\
-4 \cdot 2 \\
2 \cdot 1\end{array}$ \\
\hline
\end{tabular}

*Significance assessed with paired $t$ test.

TABLE II-Mean changes in diastolic arterial pressure on standing $(\mathrm{mm} \mathrm{Hg})$

\begin{tabular}{|c|c|c|c|c|c|c|c|}
\hline & \multicolumn{7}{|c|}{ Day } \\
\hline & 1 & 2 & 3 & 4 & 5 & 6 & 7 \\
\hline $\begin{array}{l}\text { No of patients } \\
\text { Mean change } \\
\text { SEM } \\
\text { p }^{*}\end{array}$ & $\begin{array}{c}50 \\
-2.8 \\
1.8\end{array}$ & $\begin{array}{c}4^{E} \\
-2.5 \\
1 \cdot 7\end{array}$ & $\begin{array}{l}\text { dural } g \\
49 \\
+0.7 \\
1.5\end{array}$ & $\begin{array}{r}44 \\
-0 \cdot 1 \\
1 \cdot 1\end{array}$ & $\begin{array}{r}47 \\
+1.2 \\
1.2\end{array}$ & $\begin{array}{c}42 \\
+2.9 \\
1.4 \\
<0.05\end{array}$ & $\begin{array}{r}27 \\
+2.4 \\
2.8\end{array}$ \\
\hline $\begin{array}{l}\text { No of patients } \\
\text { Mean change } \\
\text { SEM } \\
\text { p* }\end{array}$ & $\begin{array}{l}48 \\
-3.2 \\
1.5 \\
<0.05\end{array}$ & $\begin{array}{r}47 \\
+1.3 \\
1.7\end{array}$ & $\begin{array}{c}\text { ntrol gr } \\
49 \\
-0.3 \\
1.0\end{array}$ & $\begin{array}{r}p 8 \\
48 \\
+1.6 \\
1.0\end{array}$ & $\begin{array}{r}48 \\
-0 \cdot 3 \\
1 \cdot 7\end{array}$ & $\begin{array}{c}45 \\
-0 \cdot 1 \\
2 \cdot 0\end{array}$ & $\begin{array}{r}33 \\
+1.5 \\
1.4\end{array}$ \\
\hline
\end{tabular}

* Significance assessed with paired $t$ test.

that is, diastolic arterial pressure $+\frac{1}{3}$ pulse pressure) showed no significant difference between the groups.

Postural hypotension was similar in both groups each day after delivery and was not greater in those patients whose epidural analgesia had lasted over 10 hours. It was, however, greater during the first two days after delivery. It was almost entirely due to a fall in systolic arterial pressure, and the reduction in this pressure was significant for both groups on days 1 and 2, becoming less significant on day 4 for the epidural group and day 3 for the control group and not significant thereafter (table I). The change in diastolic arterial pressure showed no set pattern and overall was not significant for either group (table II). Comparison between the groups showed no significant difference.
The incidence of dizziness on standing up from the bed was similar in both groups $(9 \%)$; this symptom occurred only on the first two days after delivery. No patient had signs or symptoms of significant postural hypotension when discharged.

\section{Discussion}

Although the occurrence of hypotension during epidural analgesia is well known and readily explained, there has been only one report of prolonged sympathetic block. ${ }^{1}$ The authors suggested that the patient had shown an idiosyncratic response to bupivacaine, resulting in persistent sympathetic dysfunction. Possibly, however, this was just an exaggeration of a common response to epidural analgesia with bupivacaine. Prolonged sensory and motor block after such analgesia has been reported, ${ }^{2-4}$ and in the treatment of chronic pain bupivacaine often produces prolonged relief when used to block the appropriate nerve. Thus by a similar mechanism bupivacaine might produce a prolonged sympathetic block after epidural analgesia. We studied our patients for only the first six to seven days after delivery, but any tendency to postural hypotension due to sympathetic dysfunction should be apparent during this time.

Our results show that there is no significant difference in the magnitude of postural hypotension in the early puerperium whether or not the patient has received epidural analgesia. This postural hypotension, which is mainly due to a fall in systolic arterial pressure, lasts for about 48 hours and is possibly secondary to the changes in blood volume and venous tone that are taking place at that time. ${ }^{5}$ Venous pooling of blood would reduce cardiac output and thus systolic arterial pressure, while compensatory arteriolar vasoconstriction would maintain diastolic arterial pressures at the normal level.

We therefore suggest that long-term postural hypotension after epidural analgesia occurs only in exceptional cases such as that described by Briggs et $a l,{ }^{1}$ and that transient postural hypotension after delivery is no more common in patients who have received epidural analgesia than in others. All patients should be helped out of bed after delivery, and any patient who complains of dizziness should have her blood pressure recorded in the supine and erect positions until her symptoms disappear.

\section{References}

${ }^{1}$ Briggs RS, May AE, Gergis MI. Persistent orthostatic hypotension after epidural analgesia. $\mathrm{Br} \mathrm{Med} \mathcal{F}$ 1978; :892-3.

2 Steel GC, Dawkins CJM. Extradural lumbar block with bupivacaine (Marcain: LAC-43). A clinical trial in lower abdominal and perineal surgery. Anaesthesia 1968;23:14-9.

${ }^{3}$ Crawford JS. The second thousand epidural blocks in an obstetric hospital practice. Br f Anaesth 1972;44:1277-87.

4 Cuerden C, Buley R, Downing JW. Delayed recovery after epidural block in labour: a report of four cases. Anaesthesia 1977 ;32:773-6.

5 Goodrich SM, Wood JE. Peripheral venous distensibility and velocity of venous blood flow during pregnancy or during oral contraceptive therapy. Am $\mathcal{F}$ Obstet Gynecol 1964 ;90:740-4.

(Accepted 28 April 1980)

ONE HUNDRED YEARS AGO At the Hertford Assizes, a clerk named Arthur Green, aged 25, was convicted of sending a threatening letter to a respectable surgeon of East Barnet, in which he demanded money as the price of his silence about an infamous offence which he alleged against the surgeon: a charge for which there was not the slightest foundation. The prisoner now admitted that his letter was groundless, and offered an apology. He was sentenced to twelve years' penal servitude. We have since been informed that this is believed not to have been his first offence; and that, in former instances, his victims have been intimidated by the horrible charge, and have submitted to extortion. In this instance, the surgeon acted promptly and boldly, and, by the skill and good conduct of Inspector Bannister of Barnet, the culprit was tracked and seized, and his serious offence proved. (British Medical fournal, 1880.) 